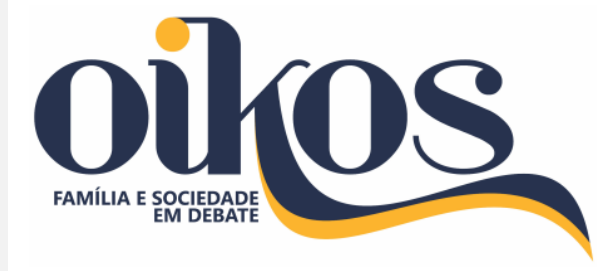

SOUZA, Ariane Figueredo; LORETO, Maria das Dores Saraiva de. Repercussões do Programa de Aquisição de Alimentos (PAA) nas condições de produção e reprodução social dos agricultores familiares. Oikos: Família e Sociedade em Debate, v. 29, n. 2, p. 230-258, 2018.

DOI: https://doi.org/10.31423/oikos.v29i2.3790

PPGED

Programa de Pós-Graduação

em Economia Doméstica

\title{
Repercussões do Programa de Aquisição de Alimentos (PAA) nas condições de produção e reprodução social dos agricultores familiares ${ }^{1}$
}

\section{Repercussions of the food Acquisition Program (PAA) on the conditions of production and social reproduction of family farmers}

\author{
Ariane Figueredo Souza 2 \\ Maria das Dores Saraiva de Loreto $^{3}$
}

\section{Resumo}

Este artigo objetivou examinar as repercussões do Programa de Aquisição de Alimentos (PAA), nas condições de produção e reprodução social dos agricultores beneficiários. Como procedimento metodológico, foi feito uso da pesquisa bibliográfica, além da aplicação de questionários e entrevistas semiestruturadas, com amostra de agricultores, do município de Paula Cândido/MG/Brasil. Para o processamento dos dados, foi feito uso do Software Statistical Package for the Social Sciences (SPSS), em sua versão 20,0. Os dados revelaram que o programa contribuiu para mudanças nos aspectos de produção e alguns componentes referentes à reprodução social das famílias agricultoras, a exemplo da renda, que viabiliza o acesso a bens materiais e, por consequência, mais conforto e estabilidade para os seus beneficiários. Todavia, os benefícios proporcionados pelo programa ainda são limitados, visto que fatores, como segurança física e condições de saúde das famílias não foram alterados, demonstrando a necessidade de integração com outras políticas sociais.

Palavras-chave: Perfil dos agricultores; Aspectos de produção; Condições de reprodução social.

\begin{abstract}
This paper aimed to examine the repercussions of the Food Acquisition Program (PAA) in the conditions of production and social reproduction of beneficiary farmers. As a methodological procedure, the use of bibliographic research was made, besides the application of questionnaires and semi-structured interviews, with sample of farmers, from the municipality of Paula Cândido/MG/Brazil. For the processing of the data, the Statistical Package for the Social Sciences (SPSS) was used in its version 20,0. The data revealed that the program contributes to changes in aspects of the production and some components related to the social reproduction of the farming families, such as income, which enables access to material goods and, consequently, more comfort and stability for its beneficiaries. However, the benefits provided by the program are still limited, since factors such as physical safety and health conditions of the families have not been modified, demonstrating the need for integration with other social policies.
\end{abstract}

Keywords: Farmers' profiles. Production aspects. Social reproduction conditions.

\footnotetext{
${ }^{1}$ O presente trabalho foi realizado com apoio da Coordenação de Aperfeiçoamento de Pessoal de Nível Superior - Brasil (CAPES).

${ }^{2}$ Mestre em Economia Doméstica pela Universidade Federal de Viçosa (UFV). E-mail: arianefigueredosouza@gmail.com

${ }^{3}$ Doutora em Economia Rural pela Universidade Federal de Viçosa (UFV). Professora do Programa de Pós-Graduação em Economia Doméstica na Universidade Federal de Viçosa (UFV). E-mail: mdora@ufv.br
} 


\section{INTRODUÇÃO}

A situação de pobreza e de desigualdades no campo tem feito com que o governo implemente políticas/programas inclusivos, que motivem a permanência das famílias no meio rural, promovam condições de produção e de atendimento às necessidades básicas mínimas dos agricultores, como é caso do Programa de Aquisição de Alimentos (PAA). Ou seja, como salientam Grisa e Schneider (2014, p. 130), as precárias condições de reprodução social dos pequenos produtores rurais têm exigido, cada vez mais, a intervenção do Estado, por meio da construção de políticas públicas adequadas às suas particularidades.

Nesse contexto, do Projeto Fome Zero emergiram diversos programas, entre eles o PAA, criado em 2003, tendo, especificamente, como objetivos a promoção da segurança alimentar de famílias que se encontram em situação de insegurança alimentar, além da abertura de mercados para a agricultura familiar e seu fortalecimento. Sobre esse último aspecto, infere-se que o programa possui condições de promover a alteração da matriz produtiva das famílias, o resgate e a valorização das práticas sociais, bem como a garantia de comercialização dos alimentos produzidos, além da satisfação e bem-estar dessas famílias, como exposto por Grisa (2009), Grisa et al. (2010), Grisa e Schneider (2014), Campos e Bianchini (2014), Grisa e Porto (2015).

Assim, conforme estudos de Silva (2013) e Zani (2014), o PAA tem surgido como grande expoente, principalmente, em termos do fortalecimento da agricultura familiar. Outras pesquisas, como de Bragatto (2010) e Carvalho (2013), destacam a importância do programa para a promoção da segurança alimentar e nutricional das famílias em situação de vulnerabilidade social. Por outro lado, Azevedo (2012) procurou verificar relação entre PAA e o empoderamento feminino; enquanto Martins e Cavalcanti (2007) ressaltaram que a implantação do PAA induziu muitos agricultores a diversificar e valorizar os produtos locais que, até então, não possuíam valor comercial. Nesse aspecto, Vogt e Souza (2009) pontuaram que o mencionado programa, ao privilegiar os canais curtos de comercialização, contribuiu para o fortalecimento das organizações da agricultura familiar e para a ampliação da sua rede social.

Especificamente, no que concerne às implicações do PAA na vida dos agricultores familiares, diversos autores, como Moreno (2012), Neto (2012) e Cunha (2015), dentre outros, consideram que o programa tenha repercussões sobre as condições de produção e reprodução social familiar, uma vez que garante a comercialização dos alimentos produzidos e, ao mesmo tempo, promove o aumento da renda das famílias. Além disso, estimula a diversificação da produção, na medida em que abrange em sua lista de aquisição diversa gama de alimentos; bem 
como contribui para o amadurecimento das associações e cooperativas, fortalecimento da agricultura familiar e, concomitantemente, para a economia e desenvolvimento local.

Agapto et al. (2012) também apresentam como resultado de seu estudo os efeitos positivos do PAA na vida dos agricultores familiares. Segundo os autores, além do aumento da renda, esse programa propiciou aos agricultores entrevistados, residentes no município de Campina do Monte Alegre (SP), a expansão das formas de comercialização, que antes estava atrelada diretamente à figura do atravessador; além de haver contribuído para a garantia da segurança alimentar e nutricional (SAN) das próprias famílias produtoras, já que começaram a diversificar a sua produção em função dessa nova possibilidade de comercialização.

Nesse sentido, o programa, para além dos ganhos econômicos, tem promovido mudanças nas relações entre produtores e consumidores; ou seja, as relações entre ambos se expandiram e se solidificaram, além de influenciar na permanência das famílias em suas propriedades, em sua autonomia e emancipação (VOGT; SOUZA, 2009, GRISA et al., 2010).

Por sua vez, Grisa (2009), Grisa et al.(2010), Grisa e Porto (2015) examinaram se o resgate de produtos e práticas tradicionais, promovido pelo PAA, trouxe impactos sobre as famílias, em termos de: inclusão social e produtiva; diversificação da produção; elevação da autoestima, por meio da valorização de saberes populares; incentivo a práticas alimentares saudáveis; fortalecimento da economia local; dentre outros.

Em função do exposto sobre a temática pesquisada, considera-se que o ganho de conhecimento do estudo em questão concentra-se no fato de analisar se a inserção das famílias agricultoras no Programa de Aquisição de Alimentos modificou aspectos e práticas inerentes à produção e contribuiu para a reprodução social ou melhoria da qualidade de vida de seus beneficiários e familiares, por meio do aumento das oportunidades e aproveitamento das capacidades existentes e experiências vivenciadas, tendo como base teórica os domínios de vida propostos por Addams (2005).

Por esse ângulo, este artigo, além de traçar o perfil pessoal e familiar dos agricultores beneficiários do PAA, no município de Paula Cândido, MG, buscou examinar de que forma o referido programa repercutiu nos aspectos de produção e reprodução social dos produtores e suas famílias.

\section{PROCEDIMENTOS METODOLÓGICOS}

A pesquisa, de natureza quanti-qualitativa, foi realizada no Estado de Minas Gerais, mais especificamente no município de Paula Cândido, pelos seguintes motivos: proximidade; 
expressividade da população residente no campo (46,7\%); relevância do setor agropecuário na economia do município (30\%); além do fato de ter o PAA em funcionamento desde o ano de 2008.

Baseando-se em Triola (2013), foi determinado o tamanho da amostra (n), para população finita, que levou em consideração o universo populacional (N); o grau de confiança desejado (estabelecido em 90\%, sendo, portanto, conforme Tabela igual a 1,65); a proporção populacional de indivíduos que pertencem ( $p$ ) e não pertencem (q) à categoria a ser estudada (p), aqui estabelecidas em 0,5 ; bem como a margem de erro (E) ou erro máximo de estimativa, delimitado em 0,1 (10\%). Assim, de acordo a população de 73 agricultores pertencentes ao PAA e as variáveis anteriormente mencionadas, o tamanho da amostra foi de 36 famílias de agricultores.

No processo de coleta dos dados, foi feito uso da pesquisa bibliográfica e documental, conjugada com questionários e entrevistas semiestruturadas, aplicadas com 36 agricultores, visando identificar o perfil pessoal e familiar, bem como suas condições de produção e reprodução social. Para tanto, foram consideradas as seguintes variáveis relativas ao perfil: gênero, raça, idade, estado civil, escolaridade, ocupação, renda, moradia, número de filhos, tamanho e tipo de família.

No que diz respeito às condições de produção, examinou-se o histórico do uso da terra, tipo de vegetação, formas de relevo e de recursos hidrográficos, tamanho da propriedade, posse da terra, assistência técnica e creditícia, preparo do solo, tipo e formas de plantio, tratos culturais mais executados, condução dos cultivos (área de pousio, rotação de cultivos), uso de irrigação, formas de colheita, total de produção e seu destino ou canais de comercialização da produção. Quanto à reprodução social foi utilizada como "proxy" a qualidade de vida, dimensionada pelos domínios de vida, propostos por Adams (2005), que foram: trabalho remunerado, renda familiar, saúde, lazer, educação, alimentação, moradia, religião, integração social, meio ambiente, família/amigos/vizinhos, bem-estar consigo mesmo.

No que concerne aos procedimentos de análise dos dados, os de natureza quantitativa, coletados por meio dos questionários, foram submetidos ao tratamento estatístico descritivo via Software Statistical Package for the Social Sciences (SPSS), em sua versão 20,0. Com relação aos dados qualitativos, obtidos por meio de entrevistas, foram transcritos, categorizados e, posteriormente, submetidos ao recurso metodológico da análise de conteúdo, proposta por Bardin (2011). 


\section{RESULTADOS E DISCUSSÃO}

\section{Perfil dos agricultores beneficiários do PAA, em Paula Cândido, MG}

Na TAB. 1 pode ser identificado o sexo dos agricultores familiares fornecedores do PAA. Dos 36 agricultores entrevistados, 20 eram mulheres, que correspondem a 55,6\%, e 16 eram homens, equivalente a $44,4 \%$ do total. A porcentagem expressiva da participação feminina no estudo pode indicar que a condução dos trabalhos na agricultura, no município estudado, já não é mais predominantemente masculina, o que vai em contramão de outros estudos, como de Cunha (2015) e Cavalcanti (2016), nos quais o perfil predominante dos agricultores familiares era do sexo masculino.

Tabela 1- Relação dos agricultores entrevistados por sexo

\begin{tabular}{ccc}
\hline & \multicolumn{3}{c}{ Frequência } \\
\hline Variáveis & (№) & $(\%)$ \\
\hline Feminino & 20 & 55,6 \\
Masculino & 16 & 44,4 \\
\hline Total & 36 & 100
\end{tabular}

Fonte: Dados da pesquisa de campo, 2017.

Importante ressaltar que essa participação pode ter sido estimulada pela criação da resolução no 44/2011, pelo Grupo Gestor do Programa de Aquisição de Alimentos, cujo objetivo foi o de fomentar a participação das mulheres no PAA, a partir do momento em que prioriza, na seleção, as propostas que tenham mulheres em sua composição, o que, muitas vezes, pode acontecer somente "no papel". Todavia, no município pesquisado, percebeu-se forte envolvimento das mulheres em todo processo produtivo, as quais percebem nesse programa oportunidade de terem a sua renda e, consequentemente, sua independência.

O segundo indicador, utilizado para caracterizar o perfil pessoal e familiar dos agricultores, diz respeito ao estado civil dos mesmos. Nota-se, conforme FIG. 1, que parte significativa dos agricultores era casada, correspondendo a $81 \%$ do total. Esse resultado está coerente com as pesquisas de Moreno (2012) e Cavalcanti (2016), que examinaram o perfil dos agricultores beneficiários do PAA e obtiveram como resultado que grande parte dos entrevistados era casada. 
Figura 1 - Estado civil dos agricultores entrevistados

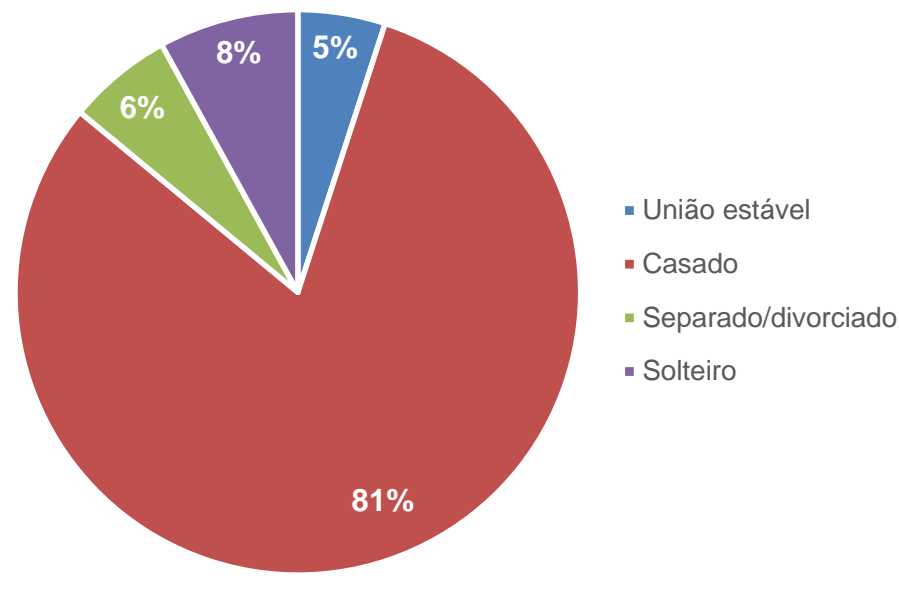

Fonte: Dados da pesquisa de campo, 2017.

A terceira medida utilizada para conhecer o perfil dos agricultores entrevistados se referiu à raça; ou seja, como cada agricultor se identificava. Dos 36 respondentes, 19 se reconhecem como sendo brancos, 15 agricultores disseram se considerar pardos e somente dois se perceberam como negros (TAB. 2).

Tabela 2 - Composição étnico racial dos agricultores entrevistados

\begin{tabular}{ccc}
\hline & \multicolumn{3}{c}{ Frequência } \\
\hline Variáveis & (№) & $(\%)$ \\
\hline Branca & 19 & 52,8 \\
Negra & 2 & 5,6 \\
Parda & 15 & 41,7 \\
\hline Total & 36 & 100
\end{tabular}

Fonte: Dados da pesquisa de campo, 2017.

A quarta variável do perfil diz respeito à religião dos produtores. A representatividade da religião católica foi quase unânime, já que, conforme Tabela 3, dos 36 agricultores, 35 afirmaram ser católico, o equivalente a $97,2 \%$.

Tabela 3 - Religião das famílias agricultoras

\begin{tabular}{ccc}
\hline & Frequência \\
\hline Variáveis & $\mathbf{( №})$ & $(\%)$ \\
\hline Católica & 35 & 97,2 \\
Não respondeu & 1 & 2,8 \\
\hline Total & 36 & 100
\end{tabular}

Fonte: Dados da pesquisa de campo, 2017. 
No que tange à composição familiar, foi possível identificar que a média do número de pessoas por domicílio foi de três, enquanto o mínimo de membros encontrados por residência foi um e o máximo de pessoas residentes na mesma moradia, foram seis.

$\mathrm{Na}$ TAB. 4, abaixo apresentada, é possível visualizar que metade das famílias possuía somente dois filhos. Esse resultado confirma tendência da atualidade, famílias cada vez menores, propiciada tanto pela alta taxa de desemprego, quanto por maior facilidade no acesso aos métodos contraceptivos ou, até mesmo, pela mudança nos arranjos familiares.

Tabela 4 - Composição étnico racial dos agricultores entrevistados

\begin{tabular}{ccc}
\hline & \multicolumn{3}{c}{ Frequência } \\
\hline № de filhos por família & (№) & $(\%)$ \\
\hline 1 & 9 & 37,7 \\
2 & 12 & 50,0 \\
3 & 2 & 0,8 \\
4 & 1 & 0,4 \\
\hline Total & 24 & 100,0 \\
\hline
\end{tabular}

Fonte: Dados da pesquisa de campo, 2017.

No que se refere à classificação das famílias agricultoras, foi possível detectar que grande parte delas pode ser considerada como nuclear, tendo em vista sua representatividade de $75 \%$, enquanto $16,7 \%$ foram classificadas como extensas e, por fim, $8,3 \%$ foram identificadas como monoparentais (TAB. 5).

Tabela 5 - Classificação das famílias agricultoras entrevistadas

\begin{tabular}{lcc}
\hline & \multicolumn{3}{c}{ Frequência } \\
\hline Família & (№) & $(\%)$ \\
\hline Nuclear & 27 & 75 \\
Extensa & 6 & 16,7 \\
Monoparental & 3 & 8,3 \\
\hline \multicolumn{1}{c}{ Total } & 36 & 100 \\
\hline
\end{tabular}

Fonte: Dados da pesquisa de campo, 2017.

Importante ressaltar que, apesar da predominância das famílias nucleares, ou seja, aquela família tradicional formada por pai, mãe e filhos, foi também evidenciada, pelo estudo, outros formatos de família existentes, como a extensa e a monoparental. Logo, o que se pretende aqui é reforçar a necessidade de elaboração de políticas públicas que compreendam a nova realidade das famílias e, a partir de então, que as políticas públicas estejam voltadas para o atendimento das suas reais necessidades, conforme aludido por Goldani (2002), ao afirmar que, para maior eficácia das políticas/programas, a elaboração e execução dos mesmos devem considerar os novos arranjos familiares existentes. 


\title{
Aspectos gerais do produtor e da propriedade
}

Para compreender como e em que condições as famílias produzem, foram realizados questionamentos diversos ao grupo de agricultores entrevistados, como, as condições de posse legal da terra, sendo que dos 36 entrevistados, 21 relataram que são os proprietários da terra, oito se identificaram como herdeiros, sete disseram possuir contrato de parceria, enquanto dois se declararam como arrendatários. No que tange à posse e formas de uso da terra, foi possível verificar que esteve presente o uso compartilhado da terra. A respeito dessa problemática há que se destacar antiga reivindicação dos trabalhadores rurais, que é a reforma agrária, conforme retratado por Graziano da Silva (1981) no parágrafo a seguir:

\begin{abstract}
A reforma agrária é para os trabalhadores rurais uma estratégia para romper o monopólio da terra e permitir que possam se apropriar um dia dos frutos do seu próprio trabalho. Para tal é necessário eliminar o latifúndio e incidir sobre dominação parasitária da terra, desde o caso daqueles que deixam a terra inculta à espera de valorização imobiliária, até os que a utilizam para repassar recursos financeiros aos Pequenos produtores rurais. (SILVA, 1981, p. 36).
\end{abstract}

Quando interrogados sobre qual era o tipo de atividade exercida em sua propriedade, mais de $70 \%$ declarou exercer somente atividades agrícolas, sendo inexpressivo o percentual daqueles que se dedicam, tanto às atividades agrícolas quanto às não agrícolas. Dentre as atividades não agrícolas citadas, situa-se o trabalho com a produção de pães, bolos e rosquinhas.

Essa pluriatividade da agricultura familiar, que consiste em combinar atividades agrícolas e não agrícolas, já era alertada por Silva (1997), ao afirmar que o meio rural brasileiro não poderia mais ser caracterizado como essencialmente agrário, visto que outras atividades, como o turismo rural, já faziam parte do cotidiano das famílias do campo, além de outras atividades exercidas fora das suas propriedades. Ressalta-se que tais formas de trabalho foram alternativas encontradas para minimizar a situação de vulnerabilidades enfrentada por essas famílias.

No que tange à assistência técnica, grande parte dos agricultores declarou receber algum tipo de assistência, cuja porcentagem foi de 77,8\%; existindo, portanto, 22,2\%, que disseram não contar com orientação ou apoio técnico. Apesar de ser porcentagem menos expressiva no município aqui estudado, a falta de assistência técnica é problema detectado em outros municípios, conforme demonstrado por Brasil (2014) e Cavalcanti (2016), o que prejudica em muito a evolução das práticas produtivas dos agricultores e, concomitantemente, 0 desenvolvimento rural. 
Igualmente, Oliveira et al. (2017) ressaltam a importância dos serviços de Assistência Técnica e Extensão Rural (ATER) para as famílias agricultoras, por contribuírem de forma significativa tanto na confecção quanto no monitoramento dos projetos e programas governamentais. Descreveram, também, o papel importante que a assistência técnica exerce para a disseminação de conhecimentos fundamentais na execução das atividades produtivas dos agricultores, já que muitos ainda possuem baixo grau de instrução.

Nesse sentido, perguntou-se também sobre a origem da assistência técnica, cujo destaque foi para a Empresa de Assistência Técnica e Extensão Rural (EMATER), já que 26 dos 28 agricultores, que alegaram ter esse tipo de apoio, fizeram menção a essa empresa. Todavia, outras organizações e instituições foram citadas, a exemplo do Movimento dos Atingidos por Barragens $(\mathrm{MAB})$ e da vigilância sanitária, conforme está ilustrado na TAB. 6, abaixo apresentada.

Tabela 6 - Prestadores de Assistência Técnica e Extensão Rural (ATER)

\begin{tabular}{lcc}
\hline & \multicolumn{3}{c}{ Frequência } \\
\hline Variáveis & (№) & $(\%)$ \\
\hline Emater & 24 & 66,7 \\
Emater e MAB & 1 & 2,8 \\
Emater e Vigilância Sanitária & 1 & 2,8 \\
Formação própria & 1 & 2,8 \\
Não respondeu & 8 & 22,2 \\
\hline \multicolumn{1}{c}{ Total } & 36 & 100,0 \\
\hline
\end{tabular}

Fonte: Dados da pesquisa de campo, 2017.

Para ter clareza quanto ao tipo de assistência prestado por essas instituições, questionouse aos entrevistados se elas ocorriam por meio de visitas, reuniões, demonstrações, excursões e, ou, cursos. Ficou evidente que as visitas técnicas na propriedade constituem a principal forma de apoio aos agricultores, pois, dos 28 agricultores, que relataram receber assistência técnica, 24 descreveram-na como sendo realizada por meio de visitas e, somente quatro relataram que as orientações aconteciam por meio de reuniões; enquanto as demais alternativas não foram mencionadas pelos entrevistados.

Outro aspecto importante sobre a capacidade produtiva dos agricultores refere-se ao acesso ao crédito, tendo sido registrado que $44,4 \%$ dos entrevistados afirmaram ter acesso a algum tipo de crédito, $52,8 \%$ disseram não ter acesso e 2,8\% não responderam à questão. Todos os que declararam possuir acesso a crédito disseram que eram oriundos do Programa Nacional de Fortalecimento da Agricultura Familiar (PRONAF).

Relativo ao histórico do uso da terra, os agricultores foram interrogados sobre o tipo de vegetação presente na propriedade, formas de relevos encontradas e tipos de hidrografias 
existentes. $\mathrm{Na}$ TAB. 7 é possível visualizar que a mata nativa é a vegetação original mais encontrada nas propriedades analisadas, além de ser a vegetação predominante em boa parte das terras. Entretanto, essa não era a única vegetação encontrada na região, já que alguns agricultores relataram possuir plantação de eucalipto em suas propriedades.

No que tange ao relevo predominante na propriedade, dos 36 entrevistados, 29 responderam que era do tipo acidentado; 16 relataram que era o plano; enquanto cinco produtores não souberam ou não responderam a questão.

Tabela 7 - Tipo de vegetação presente nas propriedades

\begin{tabular}{clcc}
\hline & \multicolumn{3}{c}{ Frequência } \\
\hline Aspectos da produção & Variáveis & $\mathbf{( N N})$ & $(\%)$ \\
\hline \multirow{2}{*}{ Vegetação original } & Mata nativa & 26 & 72,2 \\
& Não respondeu & 10 & 27,8 \\
\cline { 2 - 4 } & Total & 36 & 100 \\
\hline \multirow{3}{*}{ Vegetação predominante } & Mata nativa & 25 & 69,4 \\
& Não respondeu & 11 & 30,6 \\
\cline { 2 - 4 } & Total & 36 & 100 \\
\hline \multirow{3}{*}{ Outro tipo de vegetação } & Eucalipto & 8 & 22,2 \\
& Não possui & 28 & 77,8 \\
\cline { 2 - 4 } & Total & 36 & 100 \\
\hline
\end{tabular}

Fonte: Dados da pesquisa de campo, 2017.

Ainda sobre o histórico do uso da terra, outro questionamento foi acerca da hidrografia identificada nas propriedades, tendo ficado evidente que há variedade de formas hidrográficas e de captação de água nas propriedades rurais, a saber: brejo, córrego, nascente, poço artesiano, poço semi-artesiano, represa, ribeirão e rio.

No que diz respeito ao tamanho das propriedades pesquisadas, a média encontrada foi de 11,5 hectares (ha), sendo o tamanho mínimo de 0,7 ha e a área de maior extensão de 43,5 ha. Ressalta-se que essas propriedades, em sua grande maioria, possuíam áreas de cultivos temporários, áreas de cultivos permanentes, áreas de pastagens, áreas de matas e florestas. Quando questionados sobre a medida em hectares de cada uma dessas áreas, poucos agricultores souberam responder a questão, o que inviabilizou a análise pormenorizada desse quesito.

No que concerne à distribuição das terras, foi possível detectar que o PAA ainda não suscitou aumento da área produtiva dos beneficiários fornecedores ora entrevistados, já que todos afirmaram não ter ocorrido alteração no tamanho de suas propriedades, após a sua 
inserção no programa; resultado diferente daquele apresentado por Chmielewska et al. (2010), que apontaram para aumento da área produtiva dos agricultores participante do PAA 4 .

\section{Caracterização da produção dos agricultores do PAA}

Alusivo à caracterização da produção, uma série de aspectos foram levantados, como tipos e período de plantio; formas de preparo do solo; questionando-se, ainda, se havia ocorrido análise da água e do solo em suas propriedades; além de verificar quais os tipos de adubação mais utilizados pelos entrevistados. Tudo isso a fim de compreender, de maneira mais detalhada, a realidade vivenciada pelos agricultores; isto é, saber sobre os investimentos e cuidados tidos por eles com os alimentos que comercializavam.

Na TAB. 8 é possível vislumbrar o cuidado dos produtores com a qualidade dos alimentos cultivados, já que, quando questionados se tinham realizado análises da água e do solo em suas propriedades, mais de $60 \%$ deles afirmaram terem realizado essa prática, e aqueles que ainda não haviam realizado tais procedimentos, demonstraram preocupação em fazê-lo para atender às exigências do programa, no que tange à sanidade dos alimentos produzidos.

Tabela 8 - Aspectos sobre a qualidade da água e análise do solo

\begin{tabular}{lcc}
\hline & \multicolumn{3}{c}{ Frequência } \\
\hline Análise da água (\%) & (№) \\
\hline Não respondeu & 1 & 2,8 \\
Não & 13 & 36,1 \\
Sim & 22 & 61,1 \\
\hline Total & 36 & 100 \\
\hline Análise do solo & & 2,8 \\
Não respondeu & 1 & 25,0 \\
Não & 9 & 72,2 \\
Sim & 26 & 100
\end{tabular}

Fonte: Dados da pesquisa de campo, 2017.

Outro indicador utilizado para analisar a preocupação com os gêneros alimentícios produzidos está relacionado aos tratos culturais mais executados pelos agricultores, dado que essa prática proporciona melhores condições para o desenvolvimento das culturas. Conforme Tabela 9, dos 31 respondentes, somente dez relataram fazerem uso de herbicidas, já os 21 restantes utilizavam outro tipo de trato cultural, como: capina, roçadeira e caldas alternativas. Ressalta-se que aqueles agricultores que mencionaram o uso do herbicida demonstraram saber

${ }^{4}$ Resultado descrito no trabalho dos autores, referente a seu estudo realizado no Estado de Sergipe. 
dos riscos da utilização desses produtos, mas alegaram ser difícil não os utilizar, visto que o mesmo tem ação rápida no controle ervas daninhas.

Tabela 9 - Tipos de tratos culturais

\begin{tabular}{lcc}
\hline & \multicolumn{3}{c}{ Frequência } \\
\hline Variáveis & (№) & (\%) \\
\hline Caldas alternativas & 1 & 2,8 \\
Capina & 17 & 47,3 \\
Herbicida & 10 & 27,8 \\
Roçadeira & 8 & 22,2 \\
Roçagem/Roçada & 5 & 13,9 \\
\hline
\end{tabular}

Fonte: Dados da pesquisa de campo, 2017.

No tocante às formas de adubação utilizadas, estão presentes a adubação química e orgânica, com valores percentuais de 63,9\% e 75\%, respectivamente. Além disso, no que se refere às formas de plantio e condução dos cultivos, os dados da TAB. 10 evidenciam que boa parte dos agricultores ainda realiza o plantio de forma manual, conforme relatado por $61,1 \%$ dos entrevistados, e somente $25 \%$ dos produtores afirmaram utilizar meios mecânicos de produção. Esses valores podem estar relacionados ao gênero alimentício produzido, já que a maioria dos agricultores plantava frutas e hortaliças.

Tabela 10 - Formas de plantio e condução dos cultivos

\begin{tabular}{llcc}
\hline & & Frequência & \\
\hline & Variáveis & $\mathbf{( N o}$ ) & $(\%)$ \\
\hline \multirow{3}{*}{ Forma de Plantio } & Manual & 22 & 61,1 \\
& Mecânico & 9 & 25,0 \\
& Não se aplica (NA) & 4 & 11,1 \\
& Não respondeu & 1 & 2,8 \\
\cline { 2 - 4 } & Total & 36 & 100 \\
\hline \multirow{3}{*}{ Área de pousio } & Não se aplica (NA) & 8 & 22,2 \\
& Não & 23 & 63,9 \\
& Sim & 5 & 13,9 \\
\cline { 2 - 4 } Rotação & Total & 36 & 100 \\
& Não se aplica (NA) & 6 & 16,7 \\
& Não & 15 & 41,7 \\
& Sim & 15 & 41,7 \\
\cline { 2 - 4 } Tipos de produtos na rotação & Total & 36 & 100 \\
& Cana, milho e feijão & 1 & 2,8 \\
& Entre as hortaliças & 7 & 19,4 \\
& Milho e feijão & 7 & 19,4 \\
& Não se aplica (NA) & 21 & 58,3 \\
\cline { 2 - 4 } & Total & 36 & 100 \\
\hline
\end{tabular}

Fonte: Dados da pesquisa de campo, 2017.

Quando questionados sobre área de pousio, que é o tempo de descanso necessário para a recuperação dos nutrientes do solo, somente 13,9\% afirmaram fazer uso dessa prática. Os produtores, que não aderem a essa prática, revelaram não poderem fazê-lo, já que a área de 
cultivo deles é pequena e deixar de plantar durante determinado período de tempo poderia acarretar prejuízo. Situação similar foi descrita por Martins et al. (2014), quando afirmaram que o aumento da demanda por produtos agrícolas, na região semiárida do Brasil, contribuiu para uma redução significativa da utilização dessa técnica, o que, segundo os autores, é indispensável para a regeneração do solo.

Sobre a rotação de culturas, somente 15 dos entrevistados afirmaram realizá-la. Acreditase que ainda seja necessária maior conscientização da dimensão de práticas como essa, pois, de acordo Franchini et al. (2011), essa prática de alternância de culturas é importante para que a estabilidade da produtividade seja mantida, uma vez que a rotação de culturas impacta positivamente na qualidade física, química e biológica do solo. Logo, essa prática possibilita, além do aumento da produtividade, a redução de pragas e doenças nos cultivos.

No que concerne à irrigação, metade dos entrevistados afirmou utilizar a irrigação mecânica e a outra metade relatou ainda realizá-la de forma manual. Dentre os equipamentos mecânicos utilizados estão o microaspersor (33,3\%) e a bomba d'água $(2,8 \%)$ e, entre os instrumentos mais utilizados para irrigação manual, estão a mangueira e o regador.

Outro item analisado foi referente à forma de colheita mais utilizada pelos agricultores em suas propriedades. Nesse aspecto foi quase unânime a resposta dos entrevistados, posto que 29 agricultores afirmaram que realizam a colheita de forma manual e somente três faziam uso de maquinários para o cumprimento dessa atividade. Acredita-se que isso ocorra em função do tipo de alimentos por eles produzidos (raízes, frutas, legumes e hortaliças), que não demandam, na etapa de colheita, o trabalho com maquinários. Todavia, apesar de não demandarem o uso de equipamentos tecnológicos para a colheita, há que se ressaltar a importância dos cuidados com as demais etapas do processo produtivo, como, armazenamento, embalagem e transporte desses alimentos; nessas etapas, certamente os equipamentos podem ser cruciais para melhor conservação e qualidade desses alimentos.

No que diz respeito ao tipo de produtos produzidos, na TAB. 11 pode ser visualizada a diversidade de alimentos produzidos pelos agricultores familiares em Paula Cândido, MG, já que, aliado à capacidade produtiva dos mesmos, o programa incentiva a diversificação da produção, na medida em que abrange uma gama de alimentos em sua aquisição, que vai desde alimentos in natura até alimentos beneficiados, bem como produtos de origem animal, como aves e ovos. Ressalta-se que as frutas (35\%) constituem o principal alimento ofertado pelo PAA, na sequência estão as hortaliças (20\%), os produtos beneficiados (18,3\%), aves e ovos (11,7\%), grãos (10\%), legumes $(3,3 \%)$ e raízes $(1,7 \%)$. 
Resultado equivalente foi relatado no trabalho de Chmielewska et al. (2010), no qual os autores descrevem que o PAA proporcionou diversificação de alimentos produzidos pela agricultura familiar, além de aproveitamento de gêneros alimentícios, que eram desperdiçados em suas propriedades. Ressaltou também que a preocupação com a qualidade dos alimentos foi algo claramente observado durante a realização da pesquisa que, segundo os autores, ocorre por causa da necessidade dos fornecedores se adequarem às normas impostas pelo programa, bem como pelo compromisso gerado pela proximidade estabelecida entre os dois grupos de beneficiários, qual seja, fornecedores e consumidores.

Tabela 10 - Formas de plantio e condução dos cultivos

\begin{tabular}{|c|c|c|c|}
\hline \multirow[b]{2}{*}{ Grupos de Alimentos } & \multicolumn{3}{|c|}{ Frequência } \\
\hline & Produtos & $\left(\mathrm{N}^{\circ}\right)$ & $(\%)$ \\
\hline \multirow{7}{*}{$\begin{array}{l}\text { Frutas } \\
(n=21 ; \%=35)\end{array}$} & Goiaba & 9 & 15,0 \\
\hline & Banana & 6 & 10,0 \\
\hline & Frutas & 1 & 1,7 \\
\hline & Manga & 1 & 1,7 \\
\hline & Laranja & 1 & 1,7 \\
\hline & Abacate e Manga & 2 & 3,3 \\
\hline & Banana e mamão & 1 & 1,7 \\
\hline $\begin{array}{l}\text { Hortaliças } \\
(n=12 ; \%=20)\end{array}$ & Hortaliças & 12 & 20 \\
\hline \multirow{6}{*}{$\begin{array}{l}\text { Produtos agroindustriais } \\
(\mathrm{n}=11, \%=18,3)\end{array}$} & Broa & 5 & 8,3 \\
\hline & Doces & 1 & 1,7 \\
\hline & Goiabada & 1 & 1,7 \\
\hline & Queijo & 1 & 1,7 \\
\hline & Bolo & 2 & 3,3 \\
\hline & Fubá & 1 & 1,7 \\
\hline Aves e ovos & Frango caipira & 2 & 3,3 \\
\hline$(n=7, \%=11,7)$ & Ovos & 5 & 8,3 \\
\hline $\begin{array}{l}\text { Grãos } \\
(\mathrm{n}=6 ; \%=10)\end{array}$ & Feijão & 6 & 10,0 \\
\hline $\begin{array}{l}\text { Legumes } \\
(\mathrm{n}=2 ; \%=3,3)\end{array}$ & Legumes & 2 & 3,3 \\
\hline $\begin{array}{l}\text { Raízes } \\
(n=1 ; \%=1,7)\end{array}$ & Mandioca & 1 & 1,7 \\
\hline Total & - & 60 & 100 \\
\hline
\end{tabular}

Fonte: Dados da pesquisa de campo, 2017.

Nesse sentido, Batista et al. (2016) igualmente relataram que o PAA pode promover, ao mesmo tempo, melhorias nas condições de produção e mudanças na qualidade de vida dos agricultores fornecedores, visto que o aumento da renda da família possibilita-lhe o progresso, em termos objetivos e subjetivos; ou seja, os impactos são sentidos pelos agricultores tanto nas suas condições de produção quanto em seu bem-estar.

É relevante destacar que o município conseguiu obter o selo do Serviço de Inspeção Municipal (SIM), que fiscaliza e atesta a sanidade das unidades produtivas, dos utensílios e equipamentos utilizados para a produção/beneficiamento dos alimentos, permitindo aos 
fornecedores comercializarem com mais segurança os produtos beneficiados e, também, os de origem animal; além dos beneficiários recebedores terem a garantia de qualidade dos alimentos que serão consumidos. Conforme pode ser visto no relato de um dos líderes institucionais entrevistados.

[...] E com o tempo, também ele foi surgindo várias exigências, começou de uma forma mais light, digamos assim. Entendeu? Tranquilo, não precisava de veterinário. $O$ veterinário só dava um laudo, por exemplo, tinha produtos de origem animal, a gente começou desde o início, fornecendo frango, ovos, que aqui é uma cidade que tem tradição do pessoal do meio rural criar muita galinha, essas coisas. E, até mesmo, a própria nutricionista podia assinar como o produto era de boa qualidade né? Depois começou algumas exigências. Aí o município foi adaptando, foi adequando. E isso foi bom para o município. Foi ganho que a gente teve no município. Entendeu? Porque hoje a gente tem o SIM né? Que é o selo de inspeção municipal. Entendeu? E os agricultores também foram adaptando às normas que foram exigidas. (Entrevistado 1).

Outro aspecto avaliado em relação à produção diz respeito ao destino dos alimentos produzidos, sendo questionado aos agricultores qual era a porcentagem da sua produção destinada para cada uma dessas categorias: autoconsumo, estocagem e comercialização. Constatou-se que $100 \%$ dos agricultores entrevistados comercializavam seus produtos, sendo também expressivo o autoconsumo (72,2\%) e quase inexistente a prática de estocagem (2,8\%).

Esse resultado sobre a destinação da produção permite introduzir mais um aspecto analisado pela pesquisa, que consistiu em verificar quais eram as outras formas de comercialização acessadas pelos agricultores, além do PAA, cujo resultado está representado na TAB. 12.

Tabela 12 - Canais de comercialização acessados pelos agricultores entrevistados

\begin{tabular}{lcc}
\hline Canal de Comercialização & (No) & Frequência \\
\hline PAA & 36 & 100,0 \\
Atravessador & 1 & 2,8 \\
Comércio local & 6 & 16,7 \\
Comércio próprio na comunidade & 1 & 2,8 \\
Comércio regional & 10 & 27,8 \\
PNAE & 9 & 25,0 \\
Porta a porta & 5 & 13,9 \\
CEASA & 6 & 16,7
\end{tabular}

Fonte: Dados da pesquisa de campo, 2017.

É possível notar que a figura do atravessador aparece apenas uma vez, indo ao encontro de um dos objetivos do PAA que é proporcionar ao agricultor segurança de comercialização, de modo que tenham outras possibilidades de venda, sem a necessidade dessa intervenção do atravessador, que acarreta dependência do agricultor nos mais diferentes aspectos. Há que se destacar, ainda, a expressividade do acesso ao mercado regional em detrimento ao mercado local, já que, além de estar evidenciado nos números expressos na TAB. 12, houve também 
alguns relatos dos entrevistados de que o mercado regional era mais receptivo aos seus produtos do que o mercado do próprio município. Ressalta-se que o Programa Nacional de Alimentação Escolar (PNAE), outro mercado institucional, também é um importante canal de comercialização para os agricultores.

Assim, pode-se inferir que o PAA implicou em mudanças nos aspectos de produção, especialmente no que se refere à ampliação, programação e diversificação da produção; melhoria no cuidado com os cultivos; ou seja, contribuiu para maior diversificação e melhoria da qualidade dos alimentos produzidos, bem como para a sua comercialização que, antes do programa, eram destinados somente para o consumo.

\section{Entidades beneficiadas com a doação de alimentos pelo PAA}

A modalidade executada no município estudado é a compra com doação simultânea, cujo objetivo é adquirir os alimentos produzidos pela agricultura familiar e doá-los para as entidades socioassistenciais locais, respeitando a cultura e os hábitos de cada região. Nesse sentido, questionou-se aos agricultores entrevistados se eles sabiam qual era o principal destino dos alimentos fornecidos ao PAA. Somente um agricultor não soube responder, uma vez que todos os outros disseram saber o destino dos seus produtos, já que muitos deles faziam as entregas pessoalmente, fato que foi considerado interessante, pois esse também é um dos objetivos do PAA, qual seja, a aproximação entre os beneficiários fornecedores e consumidores. Na TAB. 13, apresentada a seguir, estão elencadas as principais instituições beneficiadas no município.

Tabela 13 - Relação das instituições e entidades beneficiadas pelo PAA

\begin{tabular}{lcc}
\hline & \multicolumn{2}{c}{ Frequência } \\
\hline Instituições e Entidades & $(\mathbf{N})$ & $(\%)$ \\
\hline Casa da Esperança & 3 & 8,3 \\
Conferência Vicentina & 23 & 63,9 \\
CRAS & 1 & 2,8 \\
Creches & 7 & 19,4 \\
Escolas municipais e estaduais do próprio município & 24 & 66,7 \\
Lar dos idosos & 2 & 5,6 \\
Novos Tempos & 2 & 5,6 \\
Não soube responder & 1 & 2,8 \\
\hline
\end{tabular}

Fonte: Dados da pesquisa de campo, 2017.

Constatou-se que, entre entidades beneficiadas, estão a Conferência Vicentina, Centro de Referência em Assistência Social (CRAS) e Lar dos Idosos, que acompanham indivíduos e famílias em situação de vulnerabilidade social; além das escolas municipais e estaduais presentes no município. Todavia, como não era o foco desse estudo, não houve o contato com 
as instituições beneficiadas para saber qual estava sendo a percepção delas sobre os benefícios trazidos pelo PAA.

\section{Componentes da Reprodução Social dos Agricultores Familiares}

O processo de busca pela satisfação das necessidades consideradas básicas, como se alimentar e se vestir, passa, necessariamente, pela relação dos indivíduos dentro de uma comunidade/grupo, que, ao fazerem parte do processo produtivo, automaticamente estão se reproduzindo socialmente. Isto significa dizer que não é possível dissociar os atos produtivos das práticas cotidianas de interatividade entre os seres.

Nesse sentido, ressalta Lessa (1999), que as oportunidades geradas a partir do trabalho acarretam relações que, para além do atendimento das necessidades materiais, promovem interações entre os indivíduos em outras esferas, como a espiritual, cultural e ideológica, que são cruciais para a sua reprodução, enquanto ser social atuante em uma sociedade complexa. Em outras palavras,

[...] todo ato de trabalho resulta em consequências que não se limitam à sua finalidade imediata. Ele também possibilita o desenvolvimento das capacidades humanas, das forças produtivas, das relações sociais, de modo que a sociedade se torna cada vez mais desenvolvida e complexa. É este rico, contraditório e complexo processo que, fundado pelo trabalho termina dando origem a relações entre os homens que não mais se limitam ao trabalho enquanto tal, que é denominado de reprodução social (LESSA, 1999, p. 25).

Assim, para que se possa compreender como tem ocorrido o processo de reprodução social dos agricultores familiares, foi utilizada como proxy a qualidade de vida, dimensionada pelos domínios de vida, propostos por Addams (2005), que vai ao encontro da definição de reprodução social já exposta neste estudo.

Segundo a autora, a sensação de bem-estar dos indivíduos pode variar ao longo da vida, já que, em cada época (infância, adolescência, juventude, melhor idade), as necessidades são diferentes, sejam por fatores biológicos ou sociais/culturais. Addams (2005) afirma que, diante da dificuldade em avaliar todas as esferas de vida dos indivíduos, é necessário definir um número limitado de requisitos que sejam representativos para que a análise de satisfação global com a vida possa ser efetiva.

Assim, a referida autora define os oito principais domínios de vida, baseado em estudo realizado por Cummins et al. (1996), que são: saúde, vida familiar, religião, amizades, situação financeira, tempo livre, bairro e trabalho. Salienta-se que o presente estudo teve como base os domínios descritos, mas, ainda assim, foram acrescidas algumas variáveis para uma análise mais detalhada das condições de reprodução social dos entrevistados, como: condições da 
moradia, alimentação, bem-estar e segurança física das famílias. Assim, para identificar os efeitos do PAA nas condições de vida dos agricultores, foi realizado o antes e depois de cada domínio anteriormente descrito.

A primeira variável analisada foi a formação educacional. No que tange a esse componente de vida (FIG. 2), grande parte dos agricultores ainda possui o ensino fundamental e médio, seja incompleto ou completo. Todavia, há que se destacar que dois dos agricultores entrevistados, relataram terem retomado os estudos motivados pela sua inserção no programa. Um deles está cursando o ensino fundamental e o outro cursando o ensino superior em Educação do Campo na Universidade Federal de Viçosa, em Viçosa, MG.

Figura 2 - Escolaridade dos agricultores entrevistados, antes e depois do PAA

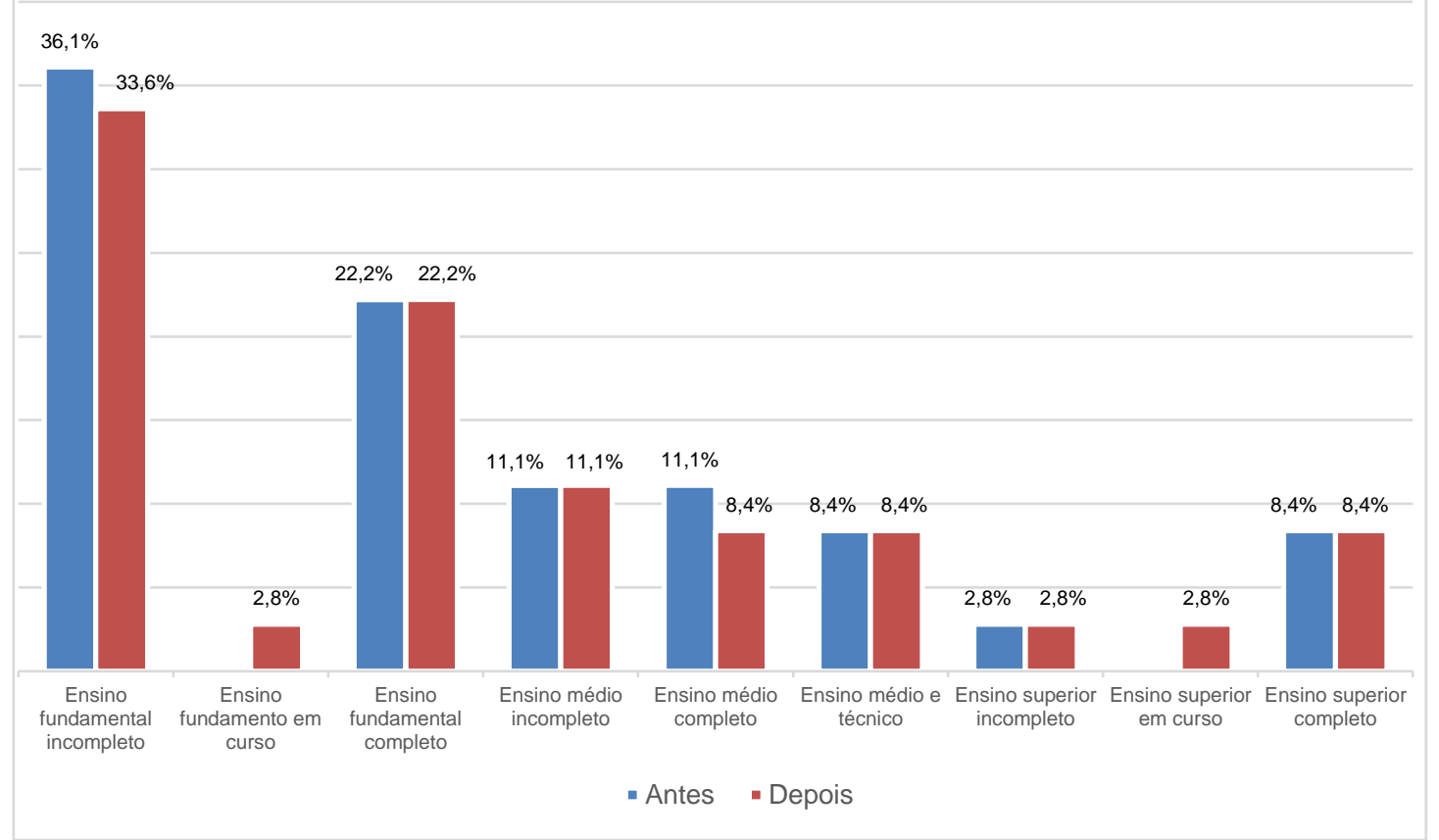

Fonte: Dados da pesquisa de campo, 2017.

Essa questão da baixa escolaridade dos agricultores remete-nos a problemática antiga, porém persistente no meio rural, já que, mesmo com alguns avanços, muitos agricultores ainda não conseguiram progredir em sua formação educacional. Essa constatação assinala limite para o desenvolvimento rural, que, para ser efetivado, requer a satisfação de um conjunto de necessidades básicas (acesso a educação, trabalho, renda, serviços de saúde, dentre outras) das pessoas que vivem no campo.

Nessa perspectiva, Vendramini (2007, p. 130) relata a importância da educação para os trabalhadores rurais, quando afirma que "[...] o processo educativo vivido instrumentaliza os trabalhadores para o seu trabalho, para a cooperação, para as lutas junto ao MST, ao partido político, à militância ecológica [...]". 
Outro elemento analisado foi a renda familiar, sendo o 5ํdomínio de vida mais importante relacionado no estudo de Addams (2005). Os agricultores foram questionados sobre a renda mensal da família antes e depois do PAA. Notou-se que a renda predominante entre os agricultores girava em torno de 1 a 2 salários mínimos ${ }^{5}$, seguidos de dois a três salários. Apesar de não muito expressiva, fica nítida a alteração na renda, pós PAA, em praticamente todas as faixas salariais (FIG. 3).

Figura 3 - Renda familiar dos agricultores, antes e depois do PAA

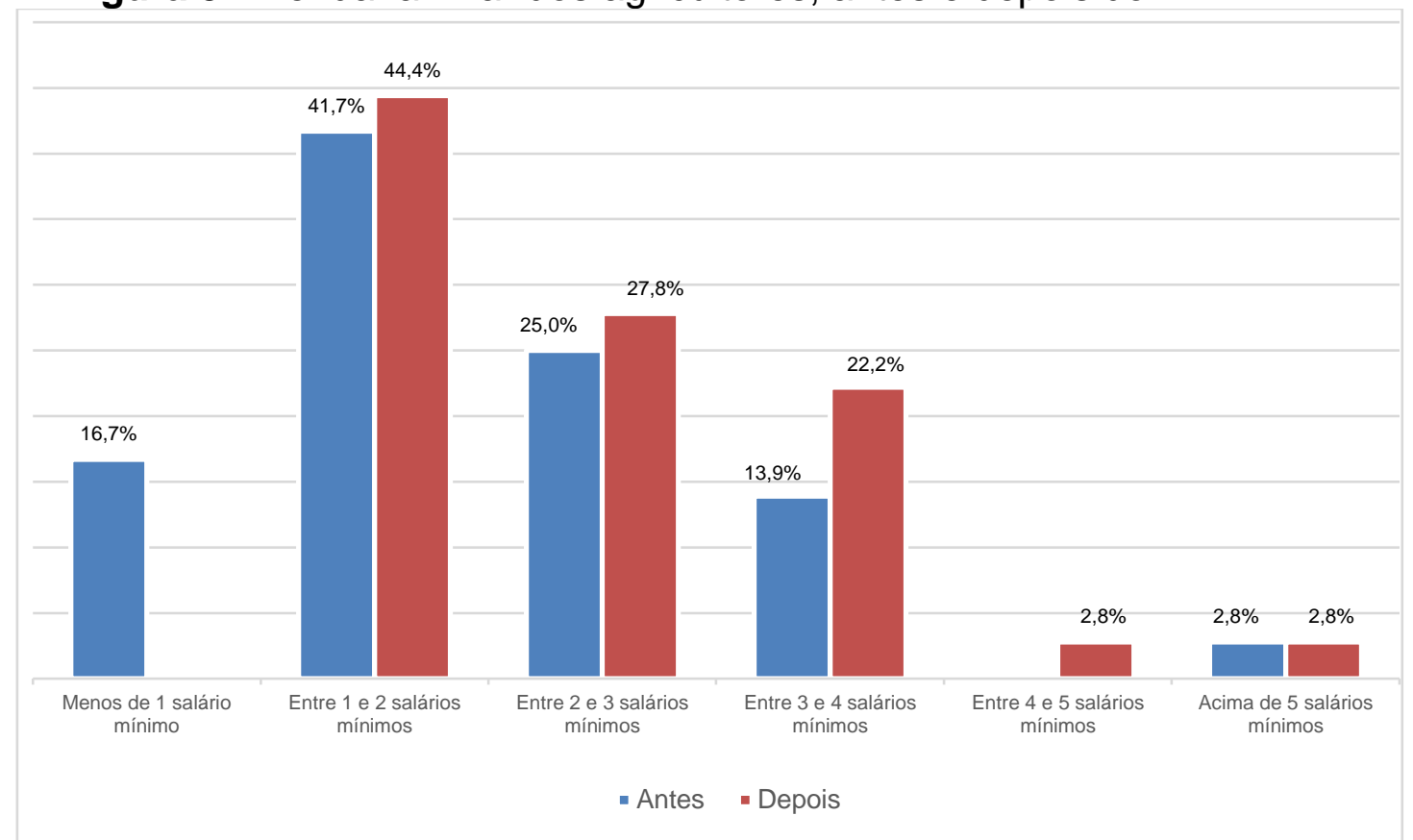

Fonte: Dados da pesquisa de campo, 2017.

Durante as entrevistas, diversos foram os relatos no sentido de que o programa não havia alterado de forma substancial os rendimentos da família, o que não diminuía a sua importância, já que grande parte dos agricultores afirmou que o lucro dos alimentos vendidos via PAA era complemento da renda familiar, como evidenciado nos depoimentos que seguem:

[...] percebo que todos os colegas estão mais motivados principalmente pela renda extra (Entrevistado 8).

[...] quando a gente tem uma renda a mais, a vida melhora (Entrevistado 12).

[...] o programa trouxe renda extra para minha família, já para muitas famílias eu vejo que o PAA é mais um complemento (Entrevistado 36).

${ }^{5}$ O salário mínimo oficial no período do estudo era de $R \$ 937,00$ (novecentos e trinta e sete reais), conforme previsto no artigo $1^{\circ}$ do Decreto no 8.948, de 29 de dezembro de 2016. 
[...] na nossa associação os produtores têm o PAA como um complemento de renda, porque a porcentagem vendida para o programa é pequena em relação ao mercado que temos pelo CEASA BH (Entrevistado 7).

Outros estudos, como o de Hespanhol (2013), evidenciam a questão do ganho com os produtos ofertados ao PAA, como sendo adicional a outras rendas que a família já possui, o que não reduz, de forma alguma, a importância do lucro obtido com esse mercado. Nas palavras da autora:

[...] o PAA tem se constituído numa alternativa em termos de complementação de renda, assegurando um valor de $\mathrm{R} \$ 4.500,00$ por produtor ao ano. Apesar de relativamente baixa (algo em torno de $\mathrm{R} \$ 375,00$ por mês), essa renda, quando combinada com outras (comercialização da produção em outros canais, recebimento da aposentadoria rural, emprego não agrícola de membros da família etc.), tem sido importante na composição do orçamento familiar [...] (HESPANHOL, 2013, p. 479).

Nesse seguimento, outro dado importante que foi coletado diz respeito à origem da renda familiar dos entrevistados, identificando-se que, dos 36 agricultores entrevistados, 30 responderam que a renda familiar não advém exclusivamente das atividades exercidas na agricultura familiar e seis relataram que viviam com a renda oriunda somente dessa atividade.

Conforme a FIG. 4, dentre as fontes de renda mais citadas, encontra-se a aposentadoria, seguida de trabalho na iniciativa privada e funcionalismo público, bem como os benefícios previdenciários, como o auxílio doença e pensão, além de benefícios assistenciais, como o bolsa família e o Benefício de Prestação Continuada (BPC).

Figura 4 - Demais fontes de renda dos agricultores do PAA

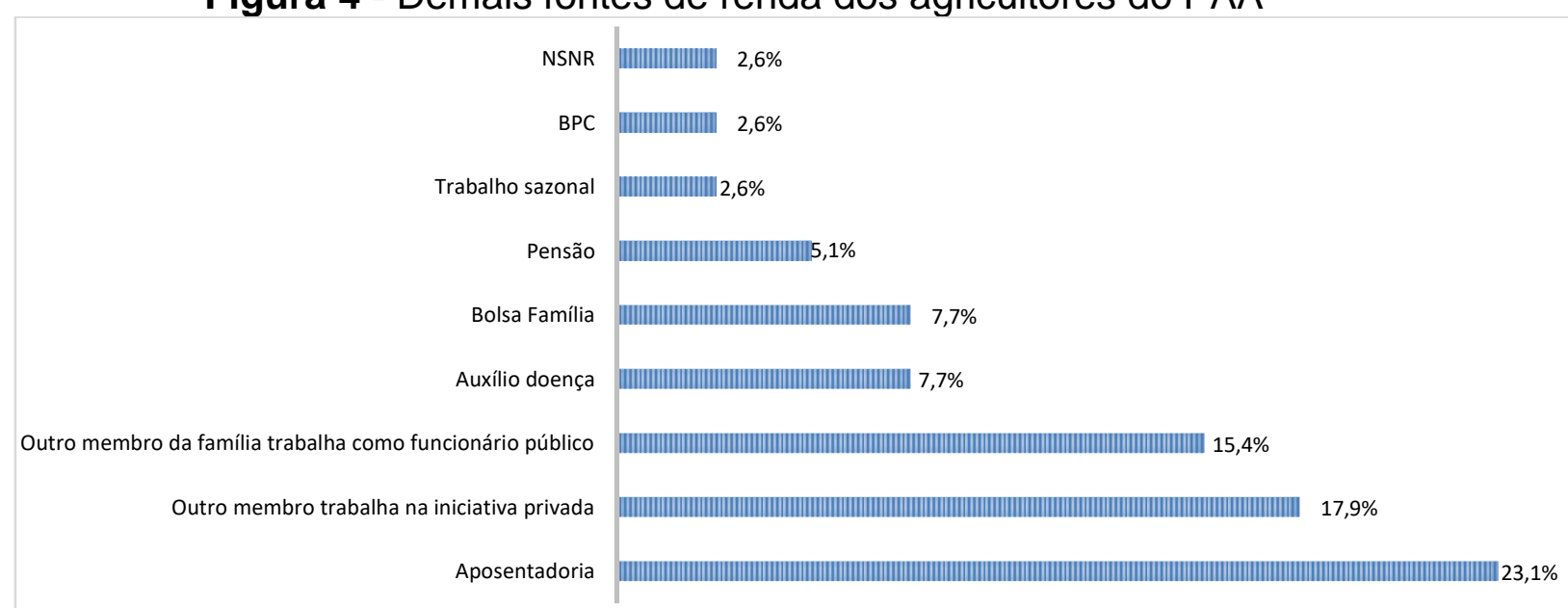

Fonte: Dados da pesquisa de campo, 2017.

Em relação às condições de moradia dos entrevistados, dos 36 respondentes, 29 afirmaram residir em casa própria, seis relataram morar em casa cedida e, somente um afirmou 
morar de aluguel. Após essa constatação questionou-se, ainda, sobre a realização de melhorias nas condições estruturais das casas após o acesso ao PAA. Com o resultado obtido, foi feita tabulação cruzada dos dados pelo programa SPSS, o que possibilitou compreensão pormenorizada dessa variável, conforme ilustrado pela TAB. 14.

Logo, tem-se que, 14 (38,9\%) produtores rurais relataram terem realizado modificações em suas residências, um (2,8\%) afirmou que realizou poucas mudanças e 21 (58,3\%) disseram que a entrada no programa não contribuiu para nenhuma benfeitoria em suas casas.

Tabela 14 - Condições e modificações na moradia com o acesso ao PAA

\begin{tabular}{llcccc} 
& & \multicolumn{3}{c}{ Condições de moradia } & \multirow{2}{*}{ Total } \\
\cline { 3 - 5 } Moradia modificada depois do PAA & Em partes & 0 & 0 & 1 & 1 \\
& Não & 1 & 2 & 18 & 21 \\
& Sim & 0 & 4 & 10 & 14 \\
\hline Totais & & $\mathbf{1}$ & $\mathbf{6}$ & $\mathbf{2 9}$ & $\mathbf{3 6}$ \\
\hline
\end{tabular}

Fonte: Dados da pesquisa de campo, 2017.

Ressalta-se que, mesmo com menor porcentagem, aqueles agricultores que tiveram a oportunidade de modificar suas residências demonstraram estar satisfeitos com o fato, como pode ser observado em alguns dos depoimentos:

[...] mudou, mudou sim, olha nós construímos essa varanda e também colocamos cerâmica (Entrevistado 10).

[...] melhorou muito! troquei o telhado da casa e coloquei esse forro (Entrevistado 14).

[...] a moradia foi modificada depois do PAA, sim, porque era aquele piso de chão batido agora até colocamos cerâmica (Entrevistado 18).

[...] sobre a moradia, melhoramos sim, construímos garagem, uma varanda nos fundos e algumas reforminhas (Entrevistado 28).

[...] a moradia modificou depois do PAA porque todo dinheiro que entra com o programa a gente investe, por exemplo, igual ali fora, a gente conseguiu melhorar a área (Entrevistado 34).

Neto (2012), em sua pesquisa, no município de Lagoa Seca - PB, ao questionar os agricultores beneficiários do PAA quais eram as mudanças sentidas em sua qualidade de vida, obteve como resposta que o aumento da renda era vantagem importante propiciada pelo programa, sobretudo, para a aquisição de bens materiais e melhorias nas suas residências; contribuindo, assim, para um conforto que antes não existia.

Ainda sobre as mudanças proporcionadas pelo PAA que, conjuntamente, impactam nas possibilidades de reprodução social das famílias, foram averiguadas as mudanças ocorridas nas 
condições de alimentação familiar, tanto em termos de quantidade, como de qualidade. Do total de famílias entrevistadas, 17 (47,2\%) alegaram terem modificado sua alimentação e 19 (52,8\%) disseram não terem observado nenhuma mudança nesse sentido, uma vez que os alimentos produzidos para o PAA já eram plantados para a subsistência familiar e faziam parte das suas cestas básicas.

Estudos, como os de Becker e Sacco dos Anjos (2010) e Chmielewska et al. (2010), corroboram com essa premissa, ao relatarem que o PAA, ao proporcionar a diversificação dos alimentos produzidos, aumenta, ao mesmo tempo, as possibilidades de alimentação dos agricultores fornecedores, cujo acesso aos alimentos saudáveis e desejáveis nutricionalmente é facilitado, pois encontram-se no quintal de suas residências.

Apurou-se, também, sobre o ambiente e as condições de trabalho dos agricultores, os quais tiveram como opções de respostas as seguintes alternativas: razoável, desfavorável e favorável. Assim, dos 36 respondentes, 22 (61,1\%) declararam que as suas condições e ambiente de trabalho já eram favoráveis antes da sua inserção no PAA e 14 (38,9\%) informaram que as condições eram razoáveis.

Todavia, há que se destacar que 35 (97,2\%) dos 36 agricultores, que expuseram avanço em suas condições de trabalho, após a entrada no programa, alegaram que, com o aumento de renda, puderam fazer melhorias em suas unidades produtivas, como investimentos em maquinários, utensílios e equipamentos de segurança; enquanto, somente 1 agricultor (2,8\%) disse que as suas condições e ambiente de trabalho permaneceram razoáveis, mesmo após o PAA.

Também foi preocupação da pesquisa saber sobre as condições de saúde das famílias agricultoras. Sobre esse quesito, 27 (75,0\%) do total dos agricultores que disseram que não possuíam plano de saúde e, somente, nove (25,0\%) afirmaram ter esse recurso. Dos que responderam negativamente à referida questão, 20 (55,6\%) alegaram que faziam uso do Sistema único de Saúde (SUS), enquanto sete (19,4\%) declararam que, além do SUS, utilizavam recursos próprios; isto é, custeavam serviços, procedimentos e, até mesmo, os medicamentos que lhes eram necessários.

Além disso, questionou-se às famílias agricultoras se a inserção no PAA havia proporcionado maiores investimentos nas suas condições de saúde. Sobre isso, dos 36 respondentes, $32(88,9 \%)$ afirmaram não terem tido nenhuma mudança nesse sentido, enquanto quatro $(11,1)$ relataram que, com a renda extra, sentiram alguns impactos positivos nas possibilidades de saúde da sua família, já que antes dependiam exclusivamente do SUS e, muitas vezes, a espera por esses serviços era demasiadamente longa. 
Outra variável que foi analisada diz respeito às condições de segurança física dos agricultores, em suas residências e propriedades, já que essa ainda é uma problemática persistente no meio rural. Nota-se, pelos números, bem como pelos relatos, que praticamente não houve alteração sobre essa questão, pois 25 (69,4\%) dos 36 respondentes relataram não terem percebido nenhuma mudança na segurança familiar, três $(8,3)$ não souberam responder a questão e, somente um (2,8\%) disse ter feito investimentos nas suas condições de segurança. Ressalta-se que 07 dos agricultores (19,4\%) foram classificados como NA (não se aplica), pois não estavam residindo no meio rural.

Quando questionados sobre as formas de violência sofrida, os relatos são exclusivamente sobre roubos e furtos em suas residências/propriedades e, até mesmo, na casa de parentes, exemplificando:

Sofri situação de violência com furto, a situação de segurança no meio rural é caótica. (Entrevistado 07)

Ah, eu nem gosto de ficar falando sobre isso não. Mas, nós já fomos roubados aqui sim, tanto é que vamo mudar pra cidade, não dá mais pra ficar aqui não. (Entrevistado 12)

Roubaram a moto do meu marido, mas, aqui em casa mesmo não teve nada não. A minha cunhada é que já passou aperto coitada, além de roubar lá na casa dela, deixou ela presa num cômodo a noite toda, sofreu demais. (Entrevistado 9)

No que tange às condições de bem-estar, foi perceptível que o PAA proporcionou maior sensação de realização às famílias agricultoras, visto que 33 entrevistados, que correspondem a $91,7 \%$ do total, declararam que esse programa contribuiu de forma substancial para o bemestar de suas famílias e, apenas três (8,3\%) afirmaram não terem percebido esse benefício. Nascimento et. al. (2017), também, fazem alusão a esse efeito do PAA; pois, segundo os autores, os agricultores demonstraram satisfação com respeito à possibilidade de:

\footnotetext{
melhoria da renda, permitindo comprar bens duráveis para melhorar o bem-estar familiar. Esse indicador é importante uma vez que a política pública auxiliou, em certa medida, na melhoria da qualidade de vida dos agricultores, cumprindo assim, com um dos objetivos do PAA [...] Alguns dos agricultores familiares revelaram que a partir do momento que iniciaram a participação no PAA, foi possível mobiliar suas residências, principalmente com a aquisição de novos eletrodomésticos (NASCIMENTO et. al., 2017, p. 97).
}

Observou-se, durante os relatos, que, geralmente, os agricultores associam bem-estar às questões financeiras e materiais, mas, para, além disso, os agricultores expuseram que o programa contribuiu com a sua realização, por proporcionar-lhes trabalhar com o que gostavam, se capacitarem, além de ajudar as pessoas que se encontram em situação de vulnerabilidade econômica e social, conforme exposto nos relatos a seguir apresentados: 
O PAA interferiu no meu bem-estar comigo mesmo porque me sinto mais útil (Entrevistado 1).

O PAA também interferiu no meu bem-estar porque desenvolvi mais (Entrevistado 3).

O PAA interferiu no meu bem-estar porque só o fato da gente poder ajudar em casa é tudo de bom, a gente fica mais feliz e motivado (Entrevistado 9).

O PAA interferiu no meu bem-estar, porque aumentou minha expectativa por melhores condições de vida (Entrevistado 13).

O PAA interferiu no meu bem-estar porque mexer com as hortaliças é uma terapia pra gente, fico de duas a três horas na horta e nem vejo o tempo passar (Entrevistado 18).

O PAA interferiu no meu bem-estar com certeza, muda muito, me sinto mais motivado (Entrevistado 21).

Quanto ao meu bem-estar, depois do PAA, me sinto melhor. Porque além do programa me favorecer eu tô favorecendo outras pessoas também, fornecendo alimentos né? De certa forma, a gente ta podendo ajudar os outros (Entrevistado 26).

Outro indicador que mereceu atenção nesse estudo, refere-se à integração social; isto é, buscou-se saber se os agricultores participavam de atividades na sua comunidade e, em caso afirmativo, quais eram elas. Com relação a isso, 32 dos 36 entrevistados afirmaram que participavam de atividades realizadas em seu meio social, enquanto quatro relataram não participar de qualquer evento. As atividades religiosas foram as que mais se destacaram nas respostas, o que pode ser explicado pela força que a religião representa na vida desses agricultores, como também pela ausência de outras opções de interatividade. Foram citadas, ainda, as atividades promovidas pela ou na associação (2), além de atividades culturais (5) e políticas (1).

Ainda sobre as variáveis relacionadas à integração social, indagou-se aos entrevistados se o PAA teria promovido melhoras nesse aspecto; assim, 30 responderam que o programa não foi vetor de maior integração entre as famílias e comunidades, enquanto três disseram que, pelo programa, ocorreu maior contato e proximidade entre as pessoas e, somente, três não souberam ou não responderam a questão.

No que tange às opções de lazer, verificou-se quais eram as alternativas mais disponíveis e acessadas, como também foi avaliado se o PAA havia interferido nesse aspecto de vida das famílias agricultoras. As alternativas que se destacaram foram: viajar, ir à casa de amigos, frequentar bares e, ou, restaurantes, seguidos de praticar algum esporte, ler livros, caminhar e fazer piqueniques.

A FIG. 5, abaixo apresentada, revela que as mudanças na integração social existiram, mas não foram tão expressivas. Nota-se que houve mudança na variável "ir à casa de amigos" 
que, antes do PAA, representava $30,6 \%$ do lazer familiar e, após o programa, passou a ter representatividade de 33,4\%; o outro item que sofreu modificação foi "ir a bares e, ou, restaurantes", que, de 19,4\% passou a representar 22,2\% do entretenimento dos agricultores e, por fim, a caminhada, que passou a ser mais praticada pelos trabalhadores após o seu ingresso no programa, uma vez que, antes do PAA, essa atividade correspondia a $2,8 \%$ do lazer dos entrevistados, enquanto, após o programa, essa porcentagem subiu para 5,6\%. Assim, em termos gerais, o programa contribuiu para maior sociabilidade dos agricultores, seja com familiares, amigos e conhecidos.

Figura 5 - Aspectos relacionados ao lazer das famílias agricultoras, antes e depois do PAA

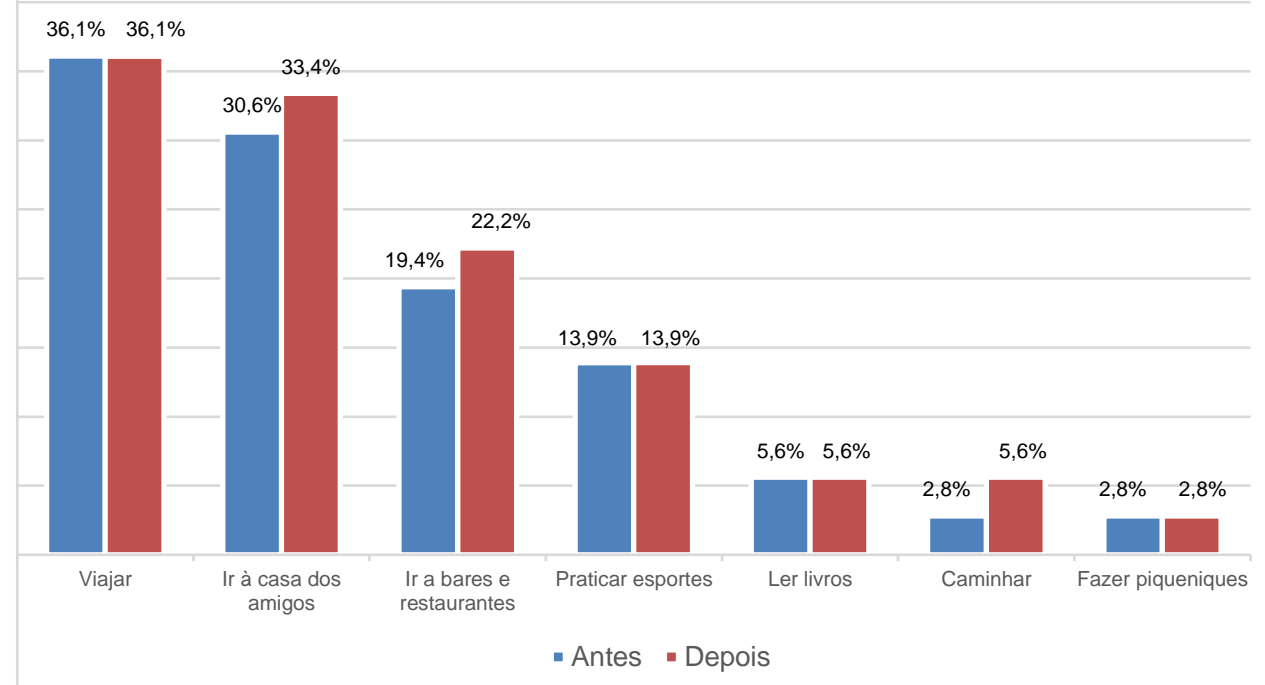

Fonte: Dados da pesquisa de campo, 2017.

Ainda sobre as formas de integração social, os agricultores foram indagados sobre vida espiritual de suas famílias; ou seja, buscou-se saber se eles participavam de missas, cultos, reuniões e pastorais da igreja. Dos 36 respondentes, 32 disseram participar ativamente de atividades relacionadas à sua religião, enquanto três afirmaram não participarem de atividades religiosas e um não soube ou não respondeu ao questionamento. Salienta-se que todos os entrevistados alegaram que o PAA não contribuiu para mudanças nesse aspecto da vida.

\section{CONSIDERAÇÕES FINAIS}

Como constatado por outros autores, no âmbito nacional, o PAA possui relevância na realidade pesquisada, pelo fortalecimento da agricultura familiar, com o aumento e diversificação da produção, construção de mercados para a comercialização dos produtos, bem como geração de renda adicional para as unidades familiares e, consequentemente, promoção da reprodução 
social, por meio do desenvolvimento das capacidades das pessoas e maior controle sobre vários domínios da vida.

Os resultados mostraram que houve alterações tanto nos modos de produção quanto de reprodução social das famílias agricultoras. Quanto aos aspectos produtivos, ressalta-se que as práticas no manejo da produção tiveram influência da assistência técnica prestada pela EMATER aos agricultores participantes do programa, proporcionando-lhes conhecimentos sobre práticas e formas de manejo produtivo e, até mesmo, orientações sobre produção programada. 0 aumento, diversificação e melhoria da qualidade de produção ampliaram as possibilidades de alimentos comercializáveis e, consequentemente, os rendimentos dos agricultores; além de aumentar a proximidade entre os produtores e consumidores, gerando confiança e sentimento de comprometimento entre ambos.

No tocante aos aspectos de reprodução social, ficou evidente que o aumento da renda foi um dos principais benefícios percebidos pelos agricultores familiares, já que a grande maioria relatou ter conseguido melhorar sua qualidade de vida a partir dessa renda adicional. Além desse componente, outros foram mencionados, como: aumento nas atividades de lazer, diversificação do consumo, melhorias nas residências e, consequentemente, mais conforto, sociabilidade e bem-estar de muitas famílias, o que se traduz em maior estabilidade quanto ao futuro de suas famílias.

Todavia, decisões político-econômicas do governo brasileiro, pelo viés neoliberal, estão conduzindo para que o programa apresente limitações e não contribua para alteração em alguns domínios da reprodução social, como é caso da segurança física e saúde das famílias agricultoras. Sendo assim, se faz necessário que ocorra o monitoramento e a avaliação do programa, para que as fragilidades sociais vivenciadas pelos agricultores familiares possam ser identificadas e minimizadas, buscando-se maior eficácia e aperfeiçoamento do programa, bem como sua integração com outras políticas sociais.

\section{REFERÊNCIAS}

ADDAMS, Jane. Age and relative importance of major life domains. Journal of Aging Studies, v. 19, n. 4, p. 503-512, $2005 . \quad$ Frossser Google

AGAPTO, João Paulo; BORSATTO, Ricardo Serra; ESQUERDO, Vanilde Ferreira de Souza; BERGAMASCO, Sonia Maria Pessoa Pereira. Avaliação do Programa de Aquisição de Alimentos (PAA) em Campina do Monte Alegre, estado de São Paulo, a partir da percepção dos agricultores. Informações Econômicas, v. 42, n. 2, p. 13-21, mar./abr., 2012. 
AZEVEDO, Vilma Maria. Os desafios para o empoderamento da mulher agricultora a partir do Programa de Aquisição de Alimentos: o caso de Barbacena - MG. Viçosa, 2012. 177f. Dissertação (Mestrado em Extensão Rural). Universidade Federal de Viçosa, 2012.

BATISTA, Lucimar Moreira Guimarães; RIBEIRO, Sônia Machado Rocha; SANTOS, Ricardo Henrique Silva; ARAÚJO, Raquel Maria Amaral; RIBEIRO, Andréia Queiroz; PRIORE, Sílvia Eloiza; DELLA LÚCIA, Ceres Mattos; LANA, Rogério de Paula; GASPARONI, Gisely Peron. Percepção de agricultores familiares do Programa de Aquisição de Alimentos (PAA) sobre o significado de fazer parte do PAA e a sua compreensão sobre conceitos relacionados à alimentação, nutrição e saúde. Saúde e Sociedade, São Paulo, v. 25, n. 2, p. 494-504, 2016. Ecrosser Google

BECKER, Cláudio; ANJOS, Flávio Sacco dos. Segurança alimentar e desenvolvimento rural: limites e possibilidades do Programa de Aquisição de Alimentos da agricultura familiar, em municípios do Sul gaúcho. Segurança Alimentar e Nutricional, v. 17, n. 1, p. 61-72, 2010. Ecrossef Google

BRAGATTO, Silvana Aparecida. Programa de Aquisição de Alimentos da agricultura familiar: segurança alimentar e inclusão social no campo?. São Paulo, 2010. 152 f. Tese (Doutorado em Nutrição Humana Aplicada). Universidade de São Paulo, 2010.

BRASIL, Lorene Kássia Barbosa. O Programa de Aquisição de Alimentos (PAA) e as transformações socioterritoriais no Rio Grande do Norte. 2014. 142 f. Dissertação (Mestrado em Geografia) - Universidade Federal do Rio Grande do Norte, Natal, 2014.

BRASIL. Decreto no 8.948, de 29 de dezembro de 2016. Regulamenta a Lei $n$ 으 13.152, de 29 de julho de 2015, que dispõe sobre o valor do salário mínimo e a sua política de valorização de longo prazo, Brasília, DF, dez 2016.

BRASIL. Resolução GGPAA no 44, de 17 de agosto de 2011. Fomenta o acesso de mulheres ao Programa de Aquisição de Alimentos. Brasília, DF, agosto 2011.

CAMARGO, Brigido Vizeu; JUSTO, Ana Maria. Tutorial para uso do software Iramuteq. 2016. 32 p. Disponível em: <http://www.iramuteq.org/documentation/fichiers/Tutorial\%20IR aMuTeQ\%20em\%20portugues_17.03.2016.pdf> Acesso em: 26 fev. 2018.

CAMPOS, Arnoldo de.; BIANCHINI, Valter. A Agricultura Familiar passa a ser uma prioridade de estado. In: DEL GROSSI, Mauro Eduardo.; KROEFF, Denise Reif. Org. PAA: 10 anos de aquisição de alimentos. Brasília, DF: MDS; Secretaria Nacional de Segurança Alimentar e Nutricional; Secretaria de Avaliação e Gestão da Informação, 2014.

CARVALHO, Luciana Rodriguez Teixeira de. Bioética e suas interfaces na promoção da segurança alimentar e nutricional: análise do programa aquisição de alimentos na visão dos atores-chave na Paraíba-PB. Brasília -DF: Universidade de Brasília, 2013. 121 f. Dissertação (Mestrado em Bioética) - Universidade de Brasília, 2013.

CAVALCANTI, Natália Thaynã Farias. Diagnóstico socioeconômico do programa de aquisição de alimentos no município de Monteiro, PB. 2016. 129 f. Dissertação (Mestrado em Agroecologia e Desenvolvimento Rural) - Universidade Federal De São Carlos, São Carlos, 2016. 
CHMIELEWSKA, Danuta; SOUZA, Darana; LOURETE, Acácio Alvarenga. O Programa de Aquisição de Alimentos da Agricultura Familiar (PAA) e as práticas dos agricultores participantes orientadas ao mercado: Estudo de Caso no Estado de Sergipe. Brasília: IPEA, 2010.

CUNHA, Wellington Alvim da. Efeitos dos programas governamentais de aquisição de alimentos para a agricultura familiar no contexto local. 2015. 150 f. Dissertação (Mestrado em Administração) - Universidade Federal de Viçosa, Viçosa, MG, 2015.

FRANCHINI, Julio Cezar; COSTA, Joaquim Mariano da; DEBIASI, Henrique; TORRES, Eleno. Importância da rotação de culturas para a produção agrícola sustentável no Paraná. Londrina: Embrapa Soja, 2011. 52 p. (Documentos I, Embrapa Soja, 327)

GOLDANI, Ana Maria. Família, gênero e políticas: famílias brasileiras nos anos 90 e seus desafios como fator de proteção. Revista Brasileira de Estudos de População, v. 19, n.1, jan./jun. 2002.

GRISA, Catia; SCHMITT, Claudia Job; MATTEI, Lauro Francisco; MALUF, Renato Sergio; LEITE, Sergio Pereira. O programa de aquisição de alimentos (PAA) em perspectiva: Apontamentos e questões para o debate. Revista Eletrônica Retratos de Assentamentos, n.13, p. 137-170, 2010. Google

GRISA, Catia. Desenvolvimento local, políticas públicas e meios de vida: uma análise do Programa de Aquisição de Alimentos (PAA). In: Sociedade Brasileira de Economia, Administração e Sociologia Rural (SOBER), Porto Alegre, 2009.

GRISA, Catia; SCHNEIDER, Sergio. Três gerações de políticas públicas para a agricultura familiar e formas de interação entre sociedade e Estado no Brasil. RESR. v. 52, Supl.1, p.125146, 2014. Ecrossef Google

GRISA, Catia; PORTO, Silvio Isopo. Dez anos de PAA: As contribuições e os desafios para o desenvolvimento rural. In: Catia Grisa [e] Sergio Schneider (org). Políticas públicas de desenvolvimento rural no Brasil. Porto Alegre: Editora da UFRGS, 2015, p. 155-180.

HESPANHOL, Rosângela Aparecida de Medeiros. Programa de Aquisição de Alimentos: Limites e potencialidades de políticas de segurança alimentar para a agricultura familiar.

Sociedade \& Natureza, Uberlândia, v. 25, n. 3, p. 469-483, 2013.

LESSA, Sergio. O processo de produção/reprodução social; trabalho e sociabilidade. In: Capacitação em Serviço Social e política social: Módulo 2. Brasília: CFESS/ Abepss/Cead/UnB, 1999. p. 20-33.

MARTINS, Sergio Paganini; CAVALCANTI, Lita Isabel. Avaliação do impacto da execução do PAA no Estado do Rio Grande do Norte. Sociedade e desenvolvimento rural. v.1, n.1, 2007. Google

MARTINS, Suzana Cláudia Silveira; PINHEIRO, Marcelo de Sousa; OLIVEIRA, Ana Vitória de; FIALHO, Jamili Silva; MARTINS, Claudia Miranda. Efeito do pousio na recuperação de um solo sob caatinga no semiárido brasileiro. Enciclopédia Biosfera, Goiânia, v. 10, n. 19, p. 21942204, 2014. 
MORENO, Blesser Tavares. Programa de Aquisição de Alimentos e seu papel no fomento a inclusão social no campo. 2012. 105 f. Dissertação (Mestrado Profissional em Avaliação de Políticas Públicas) - Universidade Federal do Ceará, Fortaleza, 2012.

NASCIMENTO, Daniel Teotonio; JOHANN, Jerry Adriani; BASSO, Dirceu. O grau de satisfação dos agricultores familiares em relação ao programa de aquisição de alimentos. RPCA, v. 11, n. 2, p 82-107, 2017. Ecrosset Google

NETO, Manuel Pereira do Nascimento. O Programa de Aquisição de Alimentos - PAA no município de Lagoa Seca - PB: análise das transformações vivenciadas na Agricultura Familiar. 2012. 151 f. Dissertação (Mestrado em Desenvolvimento Regional) - Universidade Estadual da Paraíba, João Pessoa, 2012.

OLIVEIRA, Guilherme Resende; ARAÚJO, Fernando Moreira de; QUEIROZ, Carlos César de. A importância da assistência técnica e extensão rural (Ater) e do crédito rural para a agricultura familiar em Goiás. Bol. Goia. Geogr., v. 37, n. 3, p. 528-551, 2017.

SILVA, José Graziano da. O que é questão agrária. São Paulo: Brasiliense, 1981.

SILVA, José Graziano da. O novo rural brasileiro. Nova economia, v. 7, p.43-81, 1997.

SILVA, Vilmar. O papel do programa de aquisição de alimentos-PAA-para o fortalecimento da agricultura familiar: o caso da Cooperativa da Agricultura Familiar Integrada-COOPAFI-de Capanema, PR. 2013. 208 f. Dissertação (Mestrado em Desenvolvimento Regional), Universidade Tecnológica Federal do Paraná, Pato Branco, 2013.

TRIOLA, Mario F. Introdução à estatística: atualização da tecnologia. 11. ed., Rio de Janeiro: LTC, 2013.

VENDRAMINI, Célia Regina. Educação e trabalho: reflexões em torno dos movimentos sociais do campo. Cad. Cedes, v. 27, n. 72, p. 121-135, 2007. Ecossset Google

VOGT, Silmara Patrícia Cassol; SOUZA, Renato Santos de. Mercados institucionais locais como instrumento de fortalecimento da agricultura familiar: Uma análise do Programa de Aquisição de Alimentos na Região Celeiro, RS. In: CONGRESSO DA SOCIEDADE BRASILEIRA DE ECONOMIA, 47., 2009. Porto Alegre. Anais [...] Administração e Sociologia Rural. Porto Alegre: SOBER, 2009.

ZANI, Felipe Barbosa; DA COSTA, Frederico Lustosa. Avaliação da implementação do Programa Nacional de Fortalecimento da Agricultura Familiar - novas perspectivas de análise. Revista de Administração Pública, Rio de Janeiro, v. 48, n. 4, p. 889-912, jul./ago. 2014. 